\title{
"ROLAND BARTHES Y TÚ AHORA SOIS AMIGOS": FACEBOOK Y EL MITO DE LA AMISTAD
}

\author{
"ROLAND BARTHES AND YOU ARE NOW FRIENDS": \\ FACEBOOK AND THE FRIENDSHIP MYTH
}

\author{
Israel MÁRQUEZ \\ Investigador Postdoctoral Juan de la Cierva (MINECO) \\ Universitat Oberta de Catalunya (UOC) \\ isravmarquez@gmail.com
}

Resumen: El presente artículo analiza el significado de la amistad en la red social Facebook a partir de la idea de mito de Roland Barthes. Consideramos que el uso estratégico del concepto de amistad por parte de Facebook ha creado una suerte de "mito de la amistad" en el que la amistad, un concepto muy variable histórica y culturalmente, es presentado y "normalizado" como algo fundamentalmente positivo y cuantitativo, basado en la lógica de añadir constantemente nuevos "amigos" y compartir información personal con ellos. El artículo, tal y como hizo Barthes en sus famosas Mitologías, trata de "descifrar" y "desmontar" este mito con el objetivo de traer a la superficie su sentido oculto.

Palabras clave: Amistad. Mito. Metáfora. Semiótica. Redes sociales. Facebook. Roland Barthes.

Abstract: This article analyzes the meaning of friendship in the social 
network Facebook through the concept of myth proposed by Roland Barthes. We consider that the strategic use of the concept of friendship by Facebook has created a kind of "myth of friendship" in which friendship, a historically and culturally variable concept, is presented and "normalized" as something fundamentally positive and quantitative, based on the logic of adding new "friends" and sharing personal information with them. The article, as Barthes did in his famous Mythologies, tries to "decipher" and "dismantle" this myth in order to bring to the surface its hidden meaning.

Key Words: Friendship. Myth. Metaphor. Semiotics. Social Networks. Facebook. Roland Barthes.

\section{INTRODUCCIÓN Y ESTADO DE LA CUESTIÓN}

Ensuyaclásica obra Mitologías, el semiólogo francés RolandBarthes (2009) propuso una definición de mito más allá de su sentido tradicional como relato extraordinario protagonizado por seres sobrenaturales como dioses, semidioses, monstruos o personajes fantásticos. Para la antropología cultural, los mitos forman parte del sistema de creencias de una cultura o una comunidad y sustentan la cosmovisión de un pueblo. Los relatos que dan forma a los mitos narran acontecimientos acaecidos en un tiempo primigenio y sirven para reproducir imágenes, representaciones y creencias comunes que las culturas y comunidades dan por ciertas.

En el citado libro, Barthes propuso un sentido diferente de mito en un intento por llevar este concepto más allá de su uso popular tradicional y acercarlo a los discursos de la cultura de masas contemporánea. En el prólogo que escribió para la edición de 1970, Barthes dejó claro que su intención a la hora de plantear estas nuevas "mitologías" era doble: por un lado, llevar a cabo una crítica ideológica dirigida al lenguaje de la cultura de masas; y por otro, emprender un "primer desmontaje semiológico" de ese lenguaje entendiendo estos nuevos mitos como sistemas de signos (Barthes, 2009: 
7). Barthes planteó entonces el mito como un "habla", y la mitología como un fragmento de "esa vasta ciencia de los signos que Saussure postuló hace unos cuarenta años bajo el nombre de semiología" (Barthes, 2009: 169). Para Barthes, el mito constituye "un sistema de comunicación, un mensaje" que se edifica "a partir de una cadena semiológica que existe previamente: es un "sistema semiológico segundo", esto es, un sistema de signos que queda adherido al primer sistema y que está orientado a producir una determinada representación "ideológica" haciéndola pasar por "normal" y "natural" (Barthes, 2009: 167).

A partir de esta conceptualización, algunos de los mitos estudiados por Barthes fueron la representación de los romanos en el cine, el mundo del catch, el rostro de Greta Garbo, la vuelta ciclista de Francia, la cocina ornamental, el nuevo Citroën, el arte vocal burgués, etc. Con ello, el autor francés dibujó una interesante cartografía de mitologías modernas desplegadas a lo largo del siglo XX y consiguió actualizar el concepto de mito en el contexto de una cultura de masas por aquel entonces en plena expansión.

Si Barthes vio en el lenguaje de la cultura de masas la articulación de una nueva serie de mitos modernos, consideramos que la época actual, marcada por la expansión, generalización y normalización de Internet, la web 2.0, los servicios de redes sociales y las apps móviles, está activando igualmente una nueva serie de mitos propios de esta nueva era de comunicación e interacción digital y que, como diría Barthes, necesitan ser "descifrados" y "desmontados" ágilmente. Algunos autores han tratado de desmontar algunos de estos nuevos mitos digitales, como por ejemplo Burgess y Green (2009: 23) y su crítica al "mito de la celebridad" en YouTube, mito fuertemente alimentado por la retórica del "broadcast yourself" ("retransmítete a ti mismo") característica de esta famosa plataforma de alojamiento de vídeos. Pero existen actualmente muchos otros mitos digitales que necesitan ser "desmontados" y "desenmascarados". En este trabajo nos centraremos en uno de ellos, el que consideramos como "el mito de la amistad" en la red social Facebook, un mito que muchas 
personas han terminado percibiendo como normal y natural pero que impone y normaliza una idea muy concreta de la amistad que en ningún caso representa la verdadera complejidad de esta característica forma de relación humana.

\section{LAS REDES SOCIALES Y LA AMISTAD COMO CONEXIÓN}

La amistad es un fenómeno particularmente complejo. Según el Diccionario de la Real Academia, la amistad es un "afecto, puro y desinteresado, compartida con otra persona, que nace y se fortalece con el trato". Sin embargo, este significado "oficial" o "literal" de la amistad dista mucho de retratar con claridad la complejidad de este tipo de relación humana. La amistad es una relación cuyos límites son "con frecuencia borrosos", puesto que "es difícil saber dónde empieza y dónde acaba la amistad, cuándo aparece o cuándo se convierte en otra cosa distinta" (Cucó Giner, 1995: 129). Lo mismo sucede con el término “amigo", el cual resulta especialmente difícil de definir, pudiendo abarcar una amplia gama de formas y estilos de relaciones posibles (Pahl, 2003: 19). El filósofo italiano Giorgio Agamben incide en esta dificultad de representar y definir términos como "amistad" y "amigo" al preguntarse:

¿Qué es la amistad sino una proximidad tal que no es posible hacerse de ella ni una representación ni un concepto? Reconocer a alguien como un amigo significa no poder reconocerlo como "algo". No se puede decir "amigo", como se dice "blanco", "italiano", "cálido": la amistad no es una propiedad o una cualidad de un sujeto (Agamben, 2015: 45).

Por otro lado, el significado y alcance de la amistad ha cambiado a lo largo del tiempo, por lo que debe entenderse dentro de contextos históricos y culturales determinados. En la Francia de la Europa feudal, 
por ejemplo, era típico llamar amis (amigos) a los parientes, y en Inglaterra la palabra "amigo" se aplicó tanto a parientes como a no parientes hasta el siglo XVIII, de forma que los "amigos" de una persona podían incluir a cualquiera, desde empleados hasta tutores o parientes lejanos (Pahl, 2003: 51). Así mismo, las formas de expresar la amistad cambian según las culturas. En Mali, por ejemplo, una forma de manifestar el amor entre amigos es arrojarse excrementos unos a otros, algo que en los países occidentales resulta desagradable y obsceno (Brain, 1976; Citado en Pahl, 2003: 127).

A pesar de esta marcada complejidad, la cultura de masas y el mundo digital han traído consigo una multiplicación de representaciones de la amistad en la que, como señala Pahl (2003: 15), los estilos y símbolos de la cultura contemporánea están cada vez más mediatizados por la amistad y los amigos. Como señala este autor, las revistas de estilismo y moda tienden a rodear de amigos, y no de familiares, a los consumidores objetivo, y lo mismo puede decirse de otros textos massmediáticos como el cine, la publicidad o la televisión, donde las representaciones de los amigos han sustituido en muchos casos a las representaciones de la familia y las relaciones familiares características de años anteriores (pensemos en el caso paradigmático de la serie de televisión Friends, y otras similares como Seinfeld, Sex and the City, How I Met Your Mather o The Big Bang Theory).

Lo mismo ha sucedido en el ámbito digital, siendo la amistad uno de los conceptos centrales sobre el que se han construido varias de las modernas redes sociales digitales, desde Classmates hasta Facebook (Christakis y Fowler, 2010; Kirkpatrick, 2011). Esta nueva era de la comunicación en línea, en la que la idea de amistad empieza a jugar un papel fundamental en las relaciones mediadas digitalmente, se abre con servicios creados durante la década de 1990 como Classmates o Sixdegrees. Esta última red permitía a los usuarios crear perfiles personalizados y entablar amistad con otros usuarios. Como ha señalado David Kirkpatrick (2011: 85), Sixdegrees fue “el primer negocio virtual que intentó identificar y cartografiar un conjunto 
de relaciones reales entre personas reales que usaban su nombre real". El nombre de Sixdegrees hace referencia a la famosa tesis de los "seis grados de separación" de Stanley Milgram (Travers y Milgram, 1969) y a la idea de que "todos los habitantes del planeta se pueden conectar a través de una extensa cadena de relaciones que empieza por tus amigos más inmediatos, luego pasa al siguiente grado, los amigos de tus amigos, y así hasta un sexto grado" (Kirckpatrick, 2011: 85) ${ }^{1}$.

A Sixdegress le siguieron otros servicios basados igualmente en la idea de amistad como Friends Reunited o Friendster, en cuyos nombres ya se menciona explícitamente la palabra "amigo" (friend). Friendster se convirtió en un servicio muy popular, alcanzando la cifra de más de un millón de usuarios en un año, pero pronto fue superado por una red social similar: MySpace. En realidad, MySpace imitaba muchos de los rasgos de Friendster pero fue más allá de éste en éxito y popularidad. Hacia mediados de la década del 2000, MySpace se convirtió en el sitio líder para hacer amigos y comunicarse con ellos, permitiendo la formación de amistades con personas de gustos similares a uno mismo. Es en este contexto de éxito de MySpace cuando Facebook hace su aparición, convirtiéndose rápidamente en la red social de más éxito y popularidad, primero en Estados Unidos, y más tarde, a nivel mundial.

Todos estos servicios de redes sociales centrados en la idea de la amistad contribuyeron a expandir una lógica según la cual ser amigo de alguien es añadirle como contacto a través de un perfil personalizado e interactuar (o no) digitalmente con él/ella a través de este mismo perfil. Pero fue Facebook el servicio que consiguió llevar esta lógica más lejos hasta el punto de normalizarla, naturalizarla y "mitificarla", imponiendo con ello una cierta imagen y sentido de la amistad muy alejados de la verdadera complejidad de este fenómeno.

\footnotetext{
${ }^{1}$ Como comentan Christakis y Fowler (2010: 40), el experimento de Milgram "dio pie a varias investigaciones sobre la idea de que 'el mundo es un pañuelo', estudiada por vez primera por Sola Pool y Kochen, y que caló en la cultura popular con la obra de teatro Seis grados de separación, de John Guare, y el juego "A seis grados de Kevin Bacon"”.
} 


\section{FACEBOOK Y LA CENTRALIDAD DE LA AMISTAD}

Si bien las redes sociales señaladas incidieron en la idea de amistad antes que Facebook, fue esta red social la que llevó esta idea más lejos convirtiendo la amistad en un principio fundamental de su interfaz. La diferencia de Facebook con respecto a redes sociales anteriores fue agrupar toda la variedad de contactos e interacciones digitales en torno a la idea de la amistad y bajo el término "amigo", acompañando esta decisión con una retórica de la amistad que se ha ido expandiendo y afianzando de manera progresiva. Así, cuando establecemos un nuevo contacto en esta red social, éste es directamente presentado como nuestro "amigo", como pone de manifiesto la frase "Fulanito y tú ahora sois amigos". Da igual si ese contacto es un amigo real, un conocido, un compañero de trabajo, una persona que hemos conocido una noche y nos ha enviado una solicitud de amistad, nuestro hermano, nuestra madre, nuestro padre o cualquier otro familiar. Todos pasan a ser definidos indistintamente como "amigos".

Es cierto que en los últimos años Facebook ha ido refinando esta cuestión, y hoy en día permite "saludar", "enviar un mensaje" o "seguir" a otro contacto sin necesidad de añadirle como amigo. Pero el objetivo final de la compañía es que los contactos que se relacionan a través de su red social se conviertan en algún u otro momento en "amigos", y así lo destacan cuidadosamente en su diseño de interfaz. Así, las posibilidades de "saludar", "enviar mensaje" o "seguir" (cuando el perfil es público) que observamos actualmente en la página quedan reducidas a unas pequeñas pestañas situadas en un segundo plano frente a la pestaña "agregar a amigos", que se sitúa por encima de ellas. Este llamado a "agregar a amigos" se repite nuevamente - esta vez marcado en un tono verde que lo destaca frente al resto de información - en el apartado posterior de la página, donde se nos pregunta si conocemos a la persona en cuestión - ¿Conoces a Fulanito? - y se nos sugiere que "para ver lo que comparte con sus amigos, envíale una solicitud de amistad”. Además, esta interpelación a 
enviar una solicitud de amistad al contacto que estamos visualizando se ve acompañado con información relativa al número de amigos en común que tenemos con dicho contacto, imágenes de sus perfiles de usuario y número de publicaciones nuevas que han realizado.

Como vemos, aunque Facebook permite actualmente otro tipo de representación de las interacciones que se tejen en su interior, la amistad sigue siendo el concepto central de la compañía y el tipo de relación ideal que esperan de sus usuarios, tal y como se observa en la descripción que hacen en Google Play Store de su nueva versión para Android:

- Mantén el contacto con tus amigos más rápido que nunca.

- Ve qué están haciendo tus amigos.

- Comparte actualizaciones, fotos y vídeos.

- Recibe notificaciones cuando tus amigos comparten tus publicaciones o indiquen que les gustan.

- Juega y utiliza tus aplicaciones favoritas.

\section{FACEBOOK Y LA AMISTAD INSTRUMENTAL}

El uso que hace Facebook de la amistad va más allá de esta defensa de la amistad como forma predilecta de representar la relación digital que establecemos con los demás. Junto a ello, esta red social ha acabado normalizando y naturalizando una idea muy concreta de amistad basada en la acumulación de amigos. En realidad, las redes sociales anteriores a Facebook ya impusieron esta lógica acumulativa y cuantitativa de la amistad. Pero Facebook afianzó y amplificó esta lógica a partir de un diseño de interfaz y una retórica de la amistad mucho más fuertes y explicitas.

Facebookestimulaconstantementelaformacióndenuevos contactos, es decir, de nuevos "amigos". El sistema nos recuerda permanentemente las "solicitudes de amistad" que tenemos pendientes de confirmar y nos pide "responderlas". Así mismo, nos pide revisar sus "sugerencias de 
amistad" y nos propone nuevas "personas que quizás conozcas" para que las agreguemos como amigos. Existe incluso un "día de la amistad", en el marco del cual Facebook nos recuerda lo siguiente: “¿Qué sería de nosotros sin nuestros amigos? [...] creemos que cada amistad es única $y$, en el Día de la Amistad, queremos celebrar esas conexiones especiales. Esperamos que te diviertas enviando algunos premios a tus amigos para que sepan lo que significan para ti". Este tipo de interpelación amical, si la podemos denominar así, se extiende más allá de la interfaz de Facebook para dirigirse a nuestro propio correo electrónico, donde a veces nos llegan mensajes del tipo "Encuentra a más amigos" o "Tienes más amigos en Facebook de los que crees". La interpelación a hacer nuevas amistades es, por tanto, constante, y responde a los intereses de la propia compañía de generar más datos y tráfico de información.

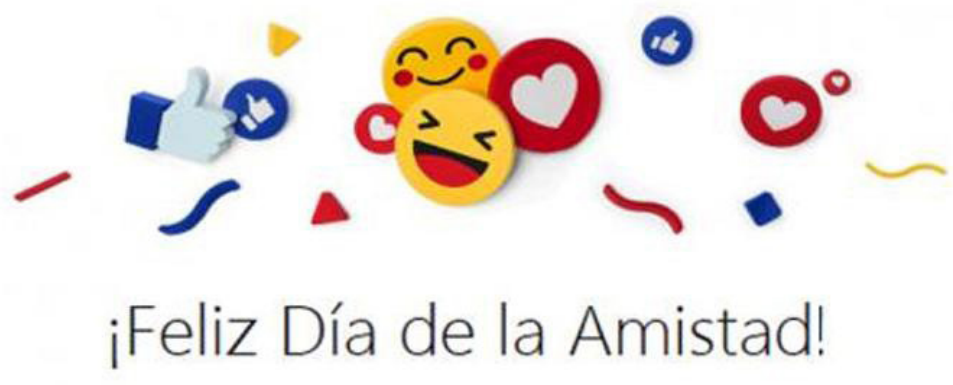

\section{En el $13 .^{\circ}$ aniversario de Facebook, queremos celebrar la amistad. Te enviaremos una notificación cuando estemos listos.}

Imagen 1. Feliz día de la amistad en el $13^{\circ}$ aniversario de Facebook Fuente: https://facebook.com

En el capítulo "Tienes 0 amigos en Facebook", de la popular y controvertida serie de animación estadounidense South Park, Cartman, uno de los cuatro jóvenes protagonistas, se dedica a dar consejos para conseguir más amigos en Facebook parodiando un segmento de la serie financiera 
Mad Money. Cartman trata las amistades como acciones similares a la bolsa, desarrollando estrategias para que las personas se hagan amigos de personas con una mayor lista de amigos, para así incrementar la propia lista. En un momento dado, habla incluso de dos amigos que van a compartir sus amigos, generando una "fusión". Los amigos son tratados en términos empresariales, según el valor al alza de cada perfil. Cartman da consejos como "salir de los círculos normales y hacer amistad con gente que no ha oído hablar de ti", "eliminar amistades con pocos números de amigos", etc., persiguiendo en todo momento subir el número de amistades. El capítulo parodia de esta manera la lógica facebookiana de tratar a los amigos como mercancía, y de medir la popularidad de cada uno según el mayor número de amigos.

Existe toda una tradición de pensamiento, rastreable desde Aristóteles, que percibe la acumulación de amigos como algo esencialmente negativo, impropio de la verdadera amistad. Aristóteles negaba el criterio cuantitativo de la amistad, esto es, el tener muchos amigos hasta la exageración, y priorizaba una idea de la amistad basada en la calidad de la misma, en tener y conservar amigos con los que realmente se pueda convivir y compartir la vida de una manera profunda y reflexiva. Son conocidas sus frases "aquel que tiene (muchos) amigos, no tiene ningún amigo”, y la más enigmática “¡Oh amigos, no hay amigos!”, la cual ha sido objeto de reflexión por parte de filósofos como Derrida (1998) o Agamben (2015).

Otro filósofo crítico con la lógica de acumular amigos fue Plutarco, especialmente en su tratado Sobre la abundancia de amigos, donde, entre otras cosas, dejo escritas cosas como lo siguiente:

la amistad reúne y junta a las personas y las mantiene unidas, estrechando sus contactos por medio de tratos y disposiciones amistosas [...] pero la amistad con muchos desune, aleja y aparta, porque, haciendo venir de nuevo y cambiando una vez hacia uno y otra vez hacia otro, no permite que haya ninguna 
unión y acercamiento de buena disposición en el trato íntimo (Plutarco, 1992: 221).

Por último, el propio refranero español, tan rico en refranes sobre la amistad y los amigos, es también crítico con esta lógica acumulativa de la amistad, con ejemplos tan significativos como los siguientes: "amigo de muchos, amigo de ninguno", "amigos y libros, pocos y escogidos", "quien tiene un amigo tiene una mina", "amigos, pocos y finos", etc².

Facebook va en contra de toda esta tradición de pensamiento y favorece y estimula la formación y acumulación de muchas amistades. No interesa la calidad de la amistad sino su cantidad, es decir, el hecho de tener y acumular más y más contactos, más y más “amigos". Facebook normaliza y naturaliza esta situación a través de su diseño interfacial y su interpelación amical, estimulando una especie de coleccionismo de amistades relacionado con el mundo empresarial y el triunfo personal y económico, tal y como encontramos en libros del tipo "Cómo ganar amigos e influir sobre las personas". Pero, como recuerda Montes:

La particular panacea "cómo hacer amigos con facilidad", tan propia del modo americano de vida, encierra una contradicción insalvable, la de que se necesite y aún sea posible tener muchos amigos, cuando lo procedente es más bien la selección, el escaso número y la calidad de los amigos que se tienen. Una persona rodeada de amigos, no solo, con toda seguridad, tendrá entre ellos algunos carentes de las condiciones mínimas para ser considerados genuinos amigos, sino que escasamente le servirá esa situación para extraer los frutos, delicados y hasta exquisitos, que la amistad es susceptible de deparar (Montes, 2007: 103).

Vemos, por tanto, que en esta tensión calidad versus cantidad de la

\footnotetext{
${ }^{2}$ Para un interesante estudio de los amigos y la amistad a través del refranero véase De Torres Ramírez (1997).
} 
amistad, Facebook se inclina claramente por la segunda, y con él muchos de los usuarios que normalizan y naturalizan el hecho de añadir más y más "amigos" a sus perfiles, sin importar cómo, cuándo ni dónde surgieron esas supuestas amistades. Con ello, Facebook instaura una visión instrumental y mercantilista de la amistad que está muy lejos de representar la complejidad y variedad de significados de esta particular forma de relación social, lo cual lleva implícito el riesgo de convertir la amistad en un signo unívoco que de alguna manera anula la "multiacentualidad" propia de todo signo (Voloshinov, 1976: 36).

En efecto, en Facebook sólo parece existir un significado o interpretación posible de la amistad: la de tener y acumular varios amigos, cuantos más mejor. De hecho, el propio sistema felicita y premia a los usuarios que logran superar un cierto número de amigos, y varios usuarios han adoptado y naturalizado esta lógica y comparten mensajes de éxito y felicidad cuando logran superar un cierto número de contactos ("¡Hoy alcancé los 3.000 amigos!'”). La amistad, aquí, nada tiene que ver con la calidad ni con otros aspectos y valores tradicionalmente vinculados a ella (intimidad, paciencia, prudencia, pausa, silencio, comprensión, sinceridad, etc.), sino que adopta un sentido puramente cuantitativo, acumulativo y estratégico cuyo resultado final no es otra cosa que la popularidad y el triunfo individuales.

\section{LA AMISTAD COMO METÁFORA}

Tras lo analizado hasta ahora, llega un momento en que nos surge la siguiente pregunta: ¿por qué la amistad?, ¿por qué esta palabra y no otra?, y sobre todo, ¿por qué este énfasis en convertirnos a todos en amigos? En su magnífico libro sobre la historia de Facebook, el periodista David Kirkpatrick recoge una importante cita de Mark Zuckerberg donde el joven fundador de Facebook admite que la palabra "amigo" resultaba útil para que la gente "superara toda una serie de obstáculos". Y lo más importante, añade Kirkpatrick, es que el uso de la palabra "amigo" acostumbró a la 
gente a "compartir mucha información sobre ellos mismos: al fin y al cabo, sólo la verían los amigos" (Kirkpatrick, 2011: 373). Es decir, al definir a todos como "amigos", según la visión de Zuckerberg, se compartirían más cosas, más datos, más información, que es el objetivo final de la compañía.

Puede verse en el pensamiento de Zuckerberg un uso estratégico de la amistad como metáfora, entendiendo que la esencia de la metáfora es, según la famosa definición de Lakoff y Johnson (1995: 41), “entender y experimentar un tipo de cosa en términos de otra". La metáfora supone el uso de una palabra por otra palabra, de un signo por otro signo, y expresa algo novedoso o no muy familiar a partir de un signo mucho más conocido y familiar. Para ello, se recurre "al repertorio del lenguaje usadero", donde, como decía Ortega y Gasset:

cada voz se encuentra ya adscrita a una significación. A fin de hacerse entender, elige la palabra cuyo usual sentido tenga alguna semejanza con la nueva significación. De esta manera, el término adquiere la nueva significación a través y por medio de la antigua, sin abandonarla. Esto es la metáfora (Ortega y Gasset, 1957: 388).

Para Jonathan Culler, la metáfora es básicamente "una versión más de un modo primordial de conocimiento: conocemos algo viéndolo como otra cosa" (Culler, 2000: 89), entendemos un signo viéndolo como otro signo. Pero la metáfora es más que todo esto. Las metáforas, como apunta Lizcano (2006), arrastran sentimientos y valores, y son capaces de modelar nuestra percepción, nuestro pensamiento y nuestras acciones. Como señala este autor: "La consolidación de ciertas metáforas es fundamental para el mantenimiento de la creencia en que 'las cosas son como son' y no de otra manera (o sea, no según otras metáforas)" (Lizcano, 2006: 29). Por eso, "la lucha por el poder es, en buena medida, una lucha por imponer las propias metáforas" (Lizcano, 2006: 70), metáforas que se expanden en espacios sociales amplios y que, de tanto usarlas, terminamos olvidando que son 
metáforas.

El pensamiento metafórico es muy útil cuando no conocemos bien un nuevo fenómeno. Por ejemplo, cuando apareció la idea de la Realidad Virtual, los investigadores recurrieron a metáforas acuáticas como "zambullirse", "sumergirse" o "inmersión" para explicar la idea de que la Realidad Virtual nos introduciría en otro ambiente (virtual), como hacemos cuando nos "sumergimos" en un ambiente acuático. En el caso de Facebook, para facilitar la comprensión de su filosofía del compartir y de su interfaz de usuario, Zuckerberg recurrió a la metáfora de la amistad y a la palabra "amigo" para que la gente se familiarizara rápidamente con ella y "superara toda una serie de obstáculos", entre ellos el de publicar y compartir información privada en la red. En Facebook, toda mi red de contactos es definida en términos de amistad, todos los contactos que tengo son mis “amigos". Por tanto, puedo decir, publicar y compartir cosas privadas, tal y como haría con mis amigos, lo que termina generando una "forma de pensamiento" (Baudrillard, 2002: 10) que asumimos como natural y que tiene su origen en ese uso metafórico de la amistad y en la idea de que compartir cosas en Facebook es como compartir cosas con nuestros verdaderos amigos, por muy íntimas y personales que sean.

La idea de amistad de Zuckerberg es una idea positiva y "felicista" (Berardi, 2003) de la misma, una amistad en la que no caben conflictos, discusiones ni controversias y en la que los "amigos" se limitan a compartir diariamente su vida personal para dar y recibir likes de otros "amigos". Por eso Facebook está construido fundamentalmente como un espacio de positividad, en el cual el enemigo, la negatividad, la infelicidad y los "no me gusta" quedan estructuralmente prohibidos y no forman parte de su diseño de interfaz. Como señala el colectivo Ippolita en este sentido:

Los "amigos" de Facebook, almenos formalmente, son individuos que comparten el amor para las mismas cosas. Nos gusta esto [...] Participaremos en este evento. Somos iguales, por eso estamos tan juntitos y nos intercambiamos posts, mensajes, fotos, 
“regalos", juguetes, poke. Los intercambios sociales se regulan siguiendo el principio de lo idéntico. La dialéctica es imposible, el conflicto está estructuralmente prohibido, la evolución (cruce, intercambio y selección de diferencias) queda bloqueada. Estamos entre nosotros porque nos reconocemos en la misma identidad; fuera, las conductas anómalas, la diversidad, no existen, no nos conciernen en absoluto (Ippolita, 2012: 27-28).

El resultado de este tipo de diseño tecnológico es la creación de un espacio "homofílico" y "asortativo" en el que los "amigos" son entendidos como personas a las que les gustan las mismas que cosas y por eso se relacionan entre sí y comparten información sobre sus vidas privadas. Se trata de una nueva manifestación del llamado efecto o "filtro burbuja" identificado por Eli Pariser. Para este autor, la nueva generación de filtros de Internet ha creado un universo de información único para cada uno de nosotros que "nos cerca con ideas con las que ya estamos familiarizados (y ya estamos de acuerdo)" (Pariser, 2017: 89), lo que limita considerablemente nuestra exposición a ideas, opiniones y realidades ajenas. En el caso de Facebook, el filtro burbuja se relaciona con lo que el propio Pariser, a partir de Eckles (2010), denomina "síndrome del mundo amigable", expresión que encierra la idea de que servicios como Facebook estarían creando actualmente un mundo amigable que bloquea cuestiones áridas, complejas y pesadas en beneficio de historias agradables y amigables. Como matiza Pariser, si bien este "síndrome del mundo amigable" es propio de servicios de filtrado como Facebook, otros espacios como Twitter, que tiene fama de dejar los filtros en manos de sus usuarios, tiende actualmente a ello:

Los usuarios de Twitter están al día de la mayoría de tuits de los colegas a los que siguen, pero si mi amigo está manteniendo un intercambio de tuits con alguien a quien yo no sigo, estos no me aparecen. La intención es totalmente inocua: Twitter está intentando no inundarme con conservaciones en las que no 
estoy interesado. Pero la consecuencia es que mientras que las charlas entre mis amigos (que tenderán a ser como yo) están excesivamente representadas, las que podrían mostrarme nuevas ideas son eclipsadas (Pariser, 2017: 151).

En un espacio de estas características, donde el conflicto queda estructuralmente prohibido a través de la metáfora de la amistad y la construcción de un espacio fundamentalmente homofílico, amigable y agradable, lo positivo es la opción por defecto. Al juntarse amistades con gustos e intereses similares, los perfiles de Facebook constituyen espacios de positividad libres de conflictos y formas negativas, las cuales, como sabemos, forman parte de las dinámicas de las relaciones de amistad. La propia interfaz de Facebook se asegura de mantener este espacio de positividad instándonos a realizar acciones positivas como "invitar a amigos a indicar que les gusta..." o "escribe un saludo de cumpleaños en su biografía...". Y todo ello a través de un eficaz manejo de la amistad como metáfora de lo que en realidad es el objetivo final de la compañía: que la gente "supere toda una serie de obstáculos" y comparta cosas, detalles íntimos de su vida privada, tal y como hacen con sus amigos reales. Así pues, un signo (la privacidad) - o varios (la privacidad, la intimidad, el compartir, el publicar, etc.) — es usado a partir de otro signo más familiar (la amistad), que oculta todo lo abstracto, complejo y problemático del signo primero a partir de un signo menos problemático y "sin obstáculos", más fácil de entender y experimentar. La metáfora de la amistad (y su sedimentación en forma de mito) trae consigo la muerte de la privacidad, y así se entiende el éxito espectacular de Facebook: un éxito tecnológico y empresarial, pero, sobre todo, un éxito de la metáfora y los signos.

\section{CONCLUSIONES}

La cultura digital, como antes la cultura de masas, ha creado nuevos mitos que requieren ser "descifrados" y "desmontados" para traer 
así a la superficie su sentido oculto, su ideología. El análisis semiótico, en tanto siempre involucra un análisis ideológico (Voloshinov, 1976), es un método privilegiado para llevar a cabo este desciframiento, tal y como hizo Barthes en sus famosas Mitologías. En este artículo nos hemos centrado en el uso estratégico del concepto de amistad por parte de la red social Facebook y la creación en base a él de lo que consideramos "el mito de la amistad", un mito en el que la amistad, un concepto muy variable histórica y culturalmente, es presentado y "normalizado" como algo fundamentalmente positivo y cuantitativo, basado en la lógica de añadir constantemente nuevos "amigos" y compartir información personal con ellos.

El uso del signo "amigo" por parte de Facebook genera la ilusión de una amistad omnipresente e igual para todos. Desde el punto de vista de la compañía todos somos amigos, sin importar que el supuesto "amigo" sea en realidad un amigo de verdad, un conocido, una persona que conocimos una noche, o un familiar. La interfaz de Facebook presenta un modelo simplista de amistad, simplifica la diversidad y complejidad de la misma a partir de una idea universal y homogénea de lo que significa ser amigo de alguien. Con ello, Facebook reduce la complejidad de uno de los tipos de relación humana más difíciles de representar, definir y precisar, porque, recordando de nuevo a Agamben (2015: 45): “¿Qué es la amistad sino una proximidad tal que no es posible hacerse de ella ni una representación ni un concepto? Reconocer a alguien como un amigo significa no poder reconocerlo como algo". Esto es precisamente lo que hace Facebook: reconocernos a todos como "amigos".

En el manejo que hace Facebook de la amistad, articulado, según vimos, como una eficaz metáfora que sustituye un signo abstracto y problemático (la privacidad) por otro mucho más familiar (la amistad) y "sin obstáculos" — recordando la expresión del propio Zuckerberg-, ciertos valores, actitudes y creencias sobre esta forma de relación humana son apoyados, mientras que otros son suprimidos. La amistad es entendida y presentada en un sentido puramente cuantitativo, acumulativo y estratégico 
que busca fundamentalmente la popularidad y el triunfo personales y que no tiene en cuenta otros aspectos y valores cualitativos tradicionalmente vinculados a ella (paciencia, prudencia, pausa, silencio, comprensión, etc.). Así mismo, la amistad es entendida como algo que todo el mundo desea y en la que no existen las discusiones y los "no me gusta", es una amistad puramente "homofílica" (Ippolita, 2012) y "felicista" (Berardi, 2003) en el que todos nos "gustamos" (like) unos a otros y en el que no hay espacio para el conflicto y la dialéctica, algo que encontramos frecuentemente en las dinámicas de amistad y que sirven para mantener, estrechar o romper los lazos amicales.

Detrás de este uso estratégico de la amistad como algo esencialmente cuantitativo y positivo se encuentran los propios intereses comerciales de la compañía liderada por Zuckerberg. A través de la metáfora de la amistad, la interfaz de Facebook oculta una ideología neoliberal que trata a los "amigos" como mercancía, números y estadísticas con las que poder comercializar y construir así su fortuna. Como ha dicho claramente el escritor estadounidense Douglas Rushkoff (2013), Facebook es en realidad una red (anti)social que "no existe para ayudarnos a hacer amigos, sino para convertir nuestra red de contactos, marcas preferidas y actividades (nuestros 'gráficos sociales') en dinero para otros". La amistad, por tanto, no funciona en Facebook como una forma desinteresada de conectarnos digitalmente con otros usuarios, sino más bien como una estrategia semiótica dirigida a motivar a la gente, a través del signo "amigo" y el famoso icono "like" o "me gusta", a publicar y compartir información sobre sus vidas personales como lo haría con sus amigos y así generar más y más datos a la compañía. Esta estrategia semiótica suprime deliberadamente otros signos problemáticos (el "enemigo", el "no me gusta", la "privacidad") para visibilizar únicamente los signos que benefician los intereses de la compañía (el "amigo", el "me gusta") y su lógica (y negocio) del compartir. Como señala Christian Fuchs en este sentido, "compartir" en Facebook significa principalmente que Facebook "comparte" información con clientes publicitarios: “Compartir' es el eufemismo para vender 
y comercializar datos" (Fuchs, 2014: 172). Y lo mismo puede decirse de la amistad: "amigo" es el eufemismo para comercializar los datos e informaciones personales que nos intercambiamos con otros "amigos" a través de esta red social.

En definitiva, Facebook no sólo ha impuesto y normalizado el uso del término "amigo" como signo predilecto que representa nuestra relación digital con los demás, sino que detrás de esta decisión semiótica y de diseño se encuentra también una determinada concepción de la amistad que elimina la pluralidad de significaciones y usos de la misma en beneficio de una visión de la amistad acorde con sus propios intereses comerciales como empresa.

\section{REFERENCIAS BIBLIOGRÁFICAS}

AGAMBEN, G. (2015). ¿Qué es un dispositivo? (seguido de El amigo y de La Iglesia y el Reino). Barcelona: Anagrama.

BARTHES, R. (2009). Mitologías. Madrid: Siglo XXI de España Editores. BAUDRILLARD, J. (2002). Contraseñas. Barcelona: Anagrama.

BERARDI, F. (2003). La fábrica de la infelicidad. Madrid: Traficantes de Sueños.

BRAIN, R. (1976). Friends and Lovers. New York: Basic Books.

BURGESS, J. \& GREEN, J. (2009). YouTube. Online Video and Participatory Culture. Cambridge: Polity Press.

CHRISTAKIS, N.A. y FOWLER, J.H.(2010). Conectados. El sorprendente poder de las redes sociales y cómo nos afectan. Barcelona: Taurus.

CUCÓ GINER, J. (1995). La amistad. Perspectiva antropológica. Barcelona: Icaria.

CULLER, J. (2000). Breve introducción a la teoría literaria. Barcelona: Crítica.

DE TORRES RAMÍREZ, I. (1997). "De los amigos y la amistad en la 
filosofía popular española”. Paremia, 6, 601-605.

DERRIDA, J. (1998). Políticas de la amistad. Madrid: Trotta.

ECKLES, D. (2010). “The 'Friendly World Syndrome' Induced by Simple Filtering Rules". Ready-to-Hand. Dan Eckles on People, Technology and Inference. Disponible en http://www.deaneckles. com/blog/386_the-friendly-world-syndrome-induced-by-simplefiltering-rules/ [20/03/2018].

FUCHS, Ch. (2014). Social Media. A Critical Introduction. London: Sage. KIRKPATRICK, D. (2011). El efecto Facebook. La verdadera historia de la empresa que está conectando el mundo. Barcelona: Gestión 2000.

IPPOLITA (2012). En el acuario de Facebook. El resistible ascenso del anarco-capitalismo. Madrid: Enclave de Libros.

LAKOFF, G. y JOHNSON, M. (1995). Metáforas de la vida cotidiana. Madrid: Cátedra.

LIZCANO, E. (2006). Metáforas que nos piensan. Sobre ciencia, democracia y otras poderosas ficciones. Madrid: Ediciones Bajo Cero / Traficantes de Sueños.

MONTES, A. C. (2007). El amor, la amistad y sus metamorfosis. Madrid: Trotta.

ORTEGA Y GASSET, J. (1957). Obras completas, vol 2. Madrid: Revista de Occidente.

PAHL, R. (2003). Sobre la amistad. Madrid: Siglo XXI de España Editores. PARISER, E. (2017). El filtro burbuja. Cómo la red decide lo que leemos y lo que pensamos. Barcelona: Taurus.

PLUTARCO (1992). Obras morales y de costumbres (Moralia) I. Madrid: Gredos.

RUSHKOFF, D. (2013). "Los motivos por los que renuncio a Facebook". CNN. Disponible en: http://cnnespanol.cnn.com/2013/02/25/losmotivos-por-los-que-renuncio-a-facebook/ [10/10/2017].

TRAVERS, J. \& MILGRAM, S. (1969). “An Experimental Study in the Small World Problem”. Sociometry 32.4, 425-443. 
"ROLAND BARTHES Y TÚ AHORA SOIS AMIGOS":

FACEBOOK Y EL MITO DE LA AMISTAD

VOLOSHINOV, V. N. (1976). El signo ideológico y la filosofía del lenguaje. Buenos Aires: Ediciones Nueva Visión.

Recibido el 12 de febrero de 2018.

Aceptado el 26 de abril de 2018. 
